\title{
Characterisation of porcine enteropathogenic Escherichia coli isolated in northeastern India
}

\author{
Hosterson Kylla ${ }^{1 凶}$, Tapan Kumar Dutta, \\ Parimal Roychoudhury, Prasant Kumar Subudhi, Lalhruaipuii, \\ Jonathan Lalsiamthara, Rajkumari Mandakini \\ Department of Veterinary Microbiology, \\ Central Agricultural University, Aizawl, Mizoram 796014, India \\ ${ }^{1}$ Disease Investigation Office, \\ Animal Husbandry \& Veterinary Department, Meghalaya, Shillong, 793002, India \\ hosterkylla123@yahoo.com
}

Received: October 4, 2019 Accepted: June 26, 2020

\begin{abstract}
Introduction: Enteropathogenic Escherichia coli (EPEC) is one of the main pathotypes causing gastroenteritis, particularly in young immunocompromised hosts. The study reports the prevalence, characterisation, and molecular epidemiology of EPEC from piglets in northeastern India. Material and Methods: A total of 457 faecal samples were collected, from which 1,286 E. coli strains were isolated and screened by PCR. The resultant EPEC strains were serotyped and phenotypically characterised for resistance against 15 antimicrobials. Also, the phylogenetic sequence was analysed for 11 selected strains. Results: A total of 42 strains (3.26\%) belonged to atypical EPEC, of which, 15 (35.71\%, and $2.29 \%$ of the 654 strains from this farm type) were isolated from organised and $27(64.29 \%$, and $4.27 \%$ of the 632 strains from this farm type) from unorganised farms; further, $5(11.90 \%$ of the EPEC strains and $1.51 \%$ of the 330 strains from this breed) were isolated from the indigenous breeds and 37 (88.10\%, and $3.87 \%$ of the 956 strains from this breed) from crossbred piglets. Serogroups O111 (11.9\%) and O118 (7.14\%) were the most prevalent of the 10 present. Sequence analysis of a length of the eaeA gene of 11 isolates of the region showed them to have $100 \%$ homology with each other and their identity ranged from $99.4 \%$ to $99.7 \%$ with GenBank reference sequences. All the EPEC isolates were multi-drug resistant, showing the highest resistance to amoxicillin (80.9\%) and cephalexin (76.19\%). Conclusion: The study highlighted the association of EPEC with piglet's diarrhoea in northeastern India. EPEC isolates belonged to many serotypes and phenotypically all were multi-drug resistant with close genetic homology.
\end{abstract}

Keywords: piglets, EPEC, virulence, serotypes, drug resistance.

\section{Introduction}

Escherichia coli is a Gram-negative, rod-shaped, flagellated, nonsporulating, facultative anaerobic bacterium belonging to the Enterobacteriaceae family and it is classified into several pathotypes based on its virulence factors $(13,31)$. Its strains range from pure commensals that may turn pathogenic in immunocompromised animals to types combining of virulence determinants sufficient for pathogenicity in different hosts including humans, mammals, and birds, and causing debilitating and sometimes fatal diseases (4). Diarrhoeagenic E. coli strains are among the most common aetiologic agents of diarrhoea $(15,24)$ and one of the pathotypes is the enteropathogenic E. coli (EPEC) producing attaching and effacing lesions caused by the intimate attachment of bacteria to the intestinal epithelial cells and effacement of enterocyte microvilli $(1,5)$. A protein called intimin mediates the bacterial attachment to outer cell membranes and is encoded by the eae gene, which is one of the genes used for the molecular diagnosis of EPEC and a key marker of EPEC infections (14).

EPEC strains are divided into typical (tEPEC) and atypical (aEPEC) subgroups depending on the respective presence or absence of the EPEC adherence 
factor plasmid carrying the $b f p$ operon $(28,30)$. Atypical EPEC are more closely related to shigatoxigenic strains and appear to be emerging pathogens $(9,30)$. It has been reported that atypical EPEC strains were commonly implicated in diarrhoea manifestation and have been isolated from different animal species and humans $(1,8)$. Infection results in production losses and mortality in piglets, seriously hampering the livestock improvement programme besides causing considerable harm to the economic viability and profitability of the swine industry. Another major concern is the emergence of drug resistant $E$. coli, one of the reasons for which is the indiscriminate use of antimicrobials, especially in foodproducing animals, particularly pigs and poultry. As compared to humans and cattle, only a limited number of surveys are available regarding porcine EPEC. Keeping in mind the importance of porcine diarrhoegenic E. coli, the present study aims to detect and molecularly characterise EPEC strains from piglets of organised and unorganised farms of northeastern India.

\section{Material and Methods}

Faecal samples. A total of 457 fresh faecal samples were collected from piglets under nine weeks of age from organised $(n=225)$ and unorganised $(\mathrm{n}=232)$ farms in the North Eastern Region Indian states of Manipur ( $\mathrm{n}=108)$, Meghalaya $(\mathrm{n}=124)$, Mizoram $(n=120)$, and Nagaland $(n=105)$ during the period of 2013-2015. Samples were collected from diarrhoeic $(n=339)$ and apparently healthy $(n=118)$ animals including crossbred $(\mathrm{n}=327)$ and indigenous $(n=130)$ piglets. For this study, the pig farms were categorised as organised and unorganised farms according to their rearing schemes. Organised pig farms were considered to be those rearing more than 50 pigs and practising an intensive system of farming, whereas; unorganised farms were semi-intensive and backyard in scale, raising 5-10 pigs.

Isolation and identification. Faecal samples were directly streaked on MacConkey's agar plates (HiMedia, Mumbai, India) for $E$. coli isolation and incubated at $37^{\circ} \mathrm{C}$ overnight. Four pink colonies were taken randomly from each plate, streaked on eosin methylene blue agar plates and subsequently incubated overnight at $37^{\circ} \mathrm{C}$. Colonies with the characteristic metallic sheen were studied for their morphological characteristics and subjected to biochemical tests such as indole, methyl red, Voges-Proskauer, citrate utilisation and hydrogen sulphide production on triple sugar iron (12). Isolates were stored as pure culture on semi-solid $\mathrm{LB}$ agar at $4^{\circ} \mathrm{C}$ and in glycerol stock at $-20^{\circ} \mathrm{C}$.

All the E. coli isolates possessing the eaeA gene were serotyped on the basis of their somatic antigen at the National Salmonella and Escherichia Centre, Central Research Institute, Kasauli, Himachal Pradesh (India).

Molecular detection of EPEC. Template DNA was prepared by a boiling and snap chilling method as per standard procedure. Molecular characterisation of E. coli isolates was performed by multiplex PCR as described by Paton and Paton (22) targeting the eaeA (384 bp), stx $(180 \mathrm{bp}), s_{2} x_{2}$ (253 bp), and hlyA (534 bp) genes. PCR was performed with a total volume of $25 \mu \mathrm{L}$ reaction mixture containing $1 \times$ PCR buffer, $100 \mathrm{mM}$ of dNTP, $1.5 \mathrm{mM}$ of $\mathrm{MgCl}_{2}, 1 \mathrm{U}$ of Taq polymerase, $20 \mathrm{pM}$ of forward and reverse primers, and $4 \mu \mathrm{L}$ of DNA template. The PCR performed in a Mastercycler Gradient thermal cycler (Eppendorf A.G., Hamburg, Germany) involved an initial denaturation step at $94^{\circ} \mathrm{C}$ for $5 \mathrm{~min}$ followed by 30 cycles of denaturation at $94^{\circ} \mathrm{C}$ for $45 \mathrm{sec}$, annealing at $61^{\circ} \mathrm{C}$ for $45 \mathrm{sec}$ and extension at $72^{\circ} \mathrm{C}$ for $45 \mathrm{sec}$; and a final extension step at $72^{\circ} \mathrm{C}$ for $10 \mathrm{~min}$. The PCR products were separated by electrophoresis on $1.5 \%$ agarose gels containing ethidium bromide $(0.5 \mu \mathrm{g} / \mathrm{mL})$ in Tris-borate buffer and using the GeneRuler $100 \mathrm{bp}$ DNA ladder (Fermentas, Vilnius, Lithuania) as a molecular size marker. The amplicons were visualised and photographed by an AlphaImager, gel documentation system (ProteinSimple, San Jose, CA, USA). All the eaeA-positive isolates were further subjected to a specific PCR for the detection of the $b f p A$ gene (426 bp) as described by Wieler et al. (32) with an initial denaturation step of $94^{\circ} \mathrm{C}$ for $5 \mathrm{~min}$ followed by 30 cycles of denaturation at $94^{\circ} \mathrm{C}$ for $1 \mathrm{~min}$, annealing at $57^{\circ} \mathrm{C}$ for $1 \mathrm{~min}$ and extension at $72^{\circ} \mathrm{C}$ for $1 \mathrm{~min}$, and a final extension step at $72^{\circ} \mathrm{C}$ for $5 \mathrm{~min}$. PCR products were separated by electrophoresis on $1.5 \%$ agarose gels and amplicons were visualised by the AlphaImager, gel documentation system.

Antimicrobial sensitivity assay. An in vitro antimicrobial susceptibility test of all EPEC isolates against 15 antimicrobial drugs (Table 1) was performed on Mueller-Hinton agar plates according to the criteria of the Clinical Laboratory Standards Institute (7). Zones of inhibition were measured using the zone size interpretative chart furnished by the manufacturer (HiMedia, India). E. coli ATCC 25922 was used as a control organism.

Cloning and sequence analysis. Extracted PCR products were gel purified and cloned in $\mathrm{pTZ} 57 \mathrm{R} / \mathrm{T}$ cloning vector using an InsTAclone PCR Cloning Kit (Thermo Scientific, Vilnius, Lithuania) and sequencing was performed at the DNA sequencing facility of the Department of Biochemistry, at the University of Delhi, India, using a 3730xl automated sequencer (Applied Biosystems, Foster city, CA, USA). Sequencing data were analysed using the MegAlign programme (DNAStar, Madison, WI, USA). Phylogenetic and bootstrap analyses were performed using neighbour joining and seqboot programmes. The 
obtained sequences were compared with other reference sequences from different sources, retrieved from the GenBank database.

\section{Results}

Isolation. A total of 1,286 E. coli were isolated from 457 faecal samples, with a higher rate of isolation from piglets from organised farms $(n=654)$ than unorganised farms $(n=632)$ of the North Eastern Region of India. A higher number of isolates $(n=1,042)$ were recovered from diarrhoeic samples than from samples of apparently healthy piglets $(\mathrm{n}=244)$.

PCR-based screening for virulence genes. Of the 1,286 E. coli isolates screened by multiplex PCR assay for the presence of the eaeA virulence gene, 42 $(3.26 \%)$ were found to possess eaeA gene (EPEC) and all were isolated only from diarrhoeic piglets. All 42 were found to be negative for the $b f p A$ gene and classified as atypical EPEC. Of these 42 EPEC isolates, $15(35.71 \%)$ were isolated from organised (15/654; $2.29 \%)$ and $27(64.29 \%)$ from unorganised farms $(27 / 632 ; 4.27 \%)$. Further, $37(88.10 \%)$ were isolated from crossbred piglets $(37 / 956 ; 3.87 \%)$ and $5(11.90 \%)$ $(5 / 330 ; 1.51 \%)$ were from the local indigenous breed.

Serotyping of EPEC. The result of serotyping the EPEC isolates based upon their somatic antigens revealed that out of 42,20 isolates $(47.62 \%)$ belonged to 10 different serogroups, 8 (19.05\%) were untypable (UT), and 14 (33.33\%) were recorded as rough strains. Serogroup O111 was found to be the most prevalent $(5 / 20,25.00 \% ; 11.90 \%$ of all EPEC isolates) followed by $\mathrm{O} 118(3 / 20,15.00 \% ; 7.14 \%$ of all EPEC isolates) and $\mathrm{O} 1, \mathrm{O} 4, \mathrm{O} 55$, and $\mathrm{O} 126$ (each 2/20, 10.00\%; $4.76 \%$ ). Only one isolate each belonged to serotypes O26, O84, O91, and O114 (each 1/20, 5.00\%; 2.38\%).

Antimicrobial drugs susceptibility. All the EPEC isolates showed resistance to at least three antimicrobial drugs (Table 1), resistance to amoxicillin
$(80.90 \%)$ being the most frequent, followed by cephalexin (76.19\%), enrofloxacin (57.14\%), ampicillin (54.76\%), piperacillin $(38.09 \%)$, nalidixic acid (23.8\%), cefixime (16.66\%), gentamicin (11.90\%), ceftazidime $(11.90 \%)$, aztreonam $(9.52 \%)$, cefotaxime (9.52\%), streptomycin (7.14\%), ciprofloxacin (4.76\%) and ceftriaxone $(4.76 \%)$. Conversely, all the isolates were sensitive to imipenem and nearly all were to ceftriaxone and ciprofloxacin (95.23\%).

Phylogenetic analysis of sequences. Annotated partial nucleotide sequences of the eaeA gene of selected isolates were deposited in GenBank and were designated the accession numbers listed in Table 2. The sequences of these 11 isolates from different areas of the North Eastern Region states of India were compared with 9 sequences retrieved from GenBank, representing the same gene from different sources and countries. Reference sequences for comparison were selected from the isolates catalogued under Enterobacteriaceae. Sequence analysis of our 11 isolates from different states of northeastern India showed $100 \%$ homology with and zero divergence from each other and one reference sequence from a pig of Indian origin (KF650779). When compared with other reference sequences from different sources, retrieved from the GenBank database, the identity of our sequences ranged from $99.4 \%$ to $99.7 \%$ (Figs 1, 2). The highest of these sequence homologies (99.7\%) were with sequences isolated from the faeces of a pig (AB647529), bird (AB647586) and human (AB647615) from Japan, human (KP197126), and chicken intestine (KP197099) from China, and cheese (HQ834728) from Brazil. Also, the eaeA sequences of $E$. coli in the present study showed $99.7 \%$ homology with those of $E$. alberti isolated from a chicken and human from China. Except for one eaeA sequence from a human (AF530555) from Australia, which was placed in a different cluster showing $88.3 \%$ identity, all the 11 sequences of the present study were grouped under one cluster along with other sequences retrieved from the GenBank database (Fig. 1).

Table 1. Antimicrobial drugs resistance pattern of EPEC from diarrhoeic faecal samples from piglets

\begin{tabular}{lll}
\hline Antibiotic disc and content & Sensitive (\%) & Resistant (\%) \\
\hline Ampicillin (AMP) $10 \mu \mathrm{g}$ & $19(45.23)$ & $23(54.76)$ \\
\hline Amoxicillin (AMX) $30 \mu \mathrm{g}$ & $8(19.04)$ & $34(80.90)$ \\
\hline Aztreonam (AT) $30 \mu \mathrm{g}$ & $38(90.47)$ & $4(9.52)$ \\
\hline Cephalexin (CN) $30 \mu \mathrm{g}$ & $10(23.80)$ & $32(76.19)$ \\
\hline Ceftazidime (CAZ) $30 \mu \mathrm{g}$ & $37(88.09)$ & $5(11.90)$ \\
\hline Cefixime (CFM) $5 \mu \mathrm{g}$ & $35(83.33)$ & $7(16.66)$ \\
\hline Ceftriaxone (CTR) $30 \mu \mathrm{g}$ & $40(95.23)$ & $2(4.76)$ \\
\hline Cefotaxime (CTX) $30 \mu \mathrm{g}$ & $38(90.47)$ & $4(9.52)$ \\
\hline Ciprofloxacin (CIP) $5 \mu \mathrm{g}$ & $40(95.23)$ & $2(4.76)$ \\
\hline Enrofloxacin (EX) $10 \mu \mathrm{g}$ & $18(42.85)$ & $24(57.14)$ \\
\hline Gentamicin (GEN) $10 \mu \mathrm{g}$ & $37(88.09)$ & $0(11.90)$ \\
\hline Imipenem (IPM) $10 \mu \mathrm{g}$ & $42(100.00)$ & $10(23.80)$ \\
\hline Nalidixic acid (NA) $30 \mu \mathrm{g}$ & $32(76.19)$ & $16(38.09)$ \\
\hline Piperacillin (PI) $10 \mu \mathrm{g}$ & $26(61.90)$ & $3(7.14)$ \\
\hline Streptomycin (S) $10 \mu \mathrm{g}$ & $39(92.85)$ & \\
\hline
\end{tabular}


Table 2. NCBI accession numbers for nucleotide sequences of the eaeA gene of different EPEC strains

\begin{tabular}{llll}
\hline No. & Organism & Serotype & GenBank accession number \\
\hline 01 & E. coli & O1 & KP987181 \\
\hline 02 & E. coli & O4 & KP987182 \\
\hline 03 & E. coli & Rough & KP987183 \\
\hline 04 & E. coli & O1 & KP987184 \\
\hline 05 & E. coli & Untypable & KP987185 \\
\hline 06 & E. coli & Untypable & KP987186 \\
\hline 07 & E. coli & O1 & KP987187 \\
\hline 08 & E. coli & Untypable & KP987188 \\
\hline 09 & E. coli & Rough & KP987189 \\
\hline 10 & E. coli & O111 & KP987190 \\
\hline 11 & E. coli & O111 & KP987191 \\
\hline
\end{tabular}

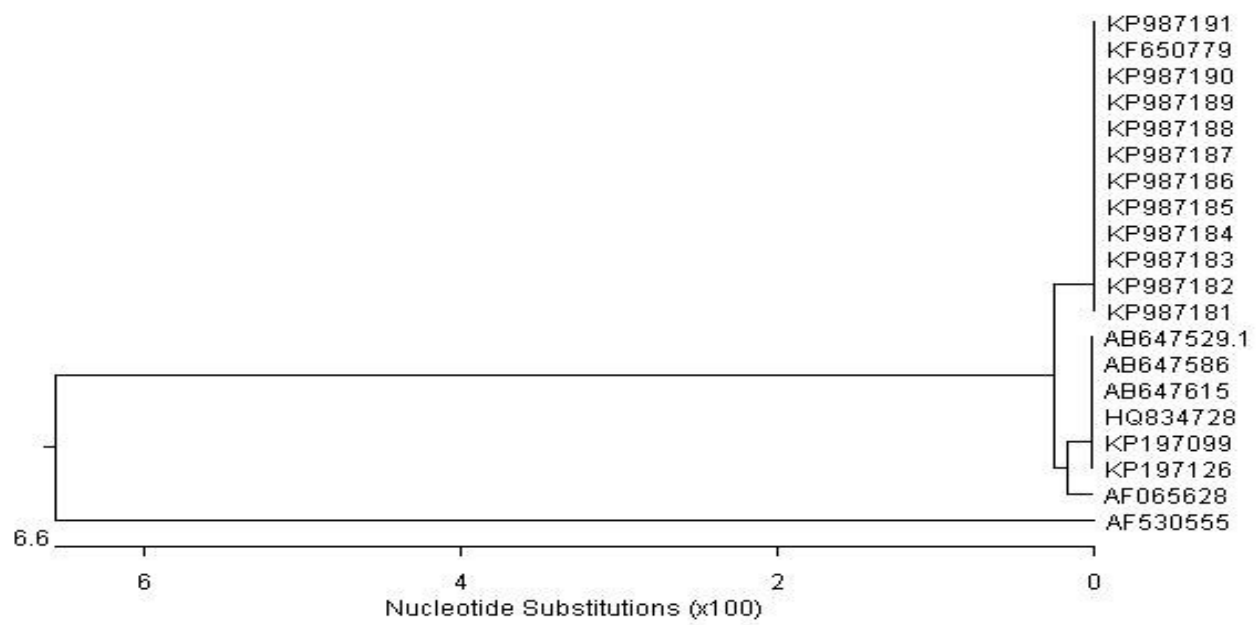

Fig. 1. Phylogenetic analysis of nucleotide sequences of the eaeA gene of $E$. Coli

Percent Identity

\begin{tabular}{|c|c|c|c|c|c|c|c|c|c|c|c|c|c|c|c|c|c|c|c|c|c|}
\hline & 1 & 2 & 3 & 4 & 5 & & & & & & & & & & & & & & & & \\
\hline 1 & & 100.0 & 100.0 & 100.0 & 100.0 & 100.0 & 1.0 & 100.0 & 1 & 0 & 100.0 & 99.7 & 1.7 & 99.7 & 1.4 & 1.3 & 8.7 & 99.7 & 97 & $1.0:$ & 1 \\
\hline 2 & 0 & & 100.0 & 100.0 & 100.0 & 100.0 & 100.0 & 100.0 & 100.0 & 100.0 & 100.0 & 99.7 & 99.7 & 99.7 & 99.4 & 88.3 & 99.7 & 99.7 & 99.7 & 100.0 & 2 \\
\hline 3 & 0.0 & 0.0 & & 100.0 & 100.0 & 100.0 & 100.0 & 100.0 & 100.0 & 100.0 & 100.0 & 99.7 & 99.7 & 99.7 & 99.4 & 88.3 & 99.7 & 99.7 & 99.7 & 100.0 & 3 \\
\hline 4 & 0.0 & 0.0 & 0.0 & & 100.0 & 100.0 & 100.0 & 100.0 & 100.0 & 100.0 & 100.0 & 99.7 & 99.7 & 99.7 & 99.4 & 88.3 & 99.7 & 99.7 & 99.7 & 100.0 & 4 \\
\hline 5 & 0.0 & 0.0 & 1.0 & 0.0 & & 100.0 & 100.0 & 100.0 & 100.0 & 100.0 & 100.0 & 99.7 & 99.7 & 99.7 & 99.4 & 88.3 & 99.7 & 99.7 & 99.7 & 100 & 5 \\
\hline 6 & 0.0 & 0.0 & 0.0 & 0.0 & 0.0 & & 100.0 & 100.0 & 100.0 & 100.0 & 100.0 & 99.7 & 99.7 & 99.7 & 99.4 & 88.3 & 99.7 & 99.7 & 99.7 & 100.0 & 6 \\
\hline 7 & 0.0 & 0.0 & 0.1 & 0.0 & 0.0 & 0.0 & & 100.0 & 100.0 & 100.0 & 100.0 & 99.7 & 99.7 & 99.7 & 99.4 & 88.3 & 99.7 & 99.7 & 99.7 & 10 & 7 \\
\hline 8 & 0.0 & 0.0 & 0.0 & 0.0 & 0.0 & 0.0 & 0.0 & & 100.0 & 100.0 & 100.0 & 99.7 & 99.7 & 99.7 & 99.4 & 88.3 & 99.7 & 99.7 & 99.7 & 100.0 & 8 \\
\hline 9 & 0.0 & 0.0 & 0.0 & 0.0 & 0.0 & 0.0 & 0.0 & 0.0 & & 100.0 & 100.0 & 99.7 & 99.7 & 99.7 & 99.4 & 8.3 & 99.7 & 99.7 & 9.7 & 100.0 & 9 \\
\hline 10 & 0.0 & 0.0 & 0.0 & 0.0 & 0.0 & 0.0 & 0.0 & 0.0 & 0.0 & & 100.0 & 99.7 & 99.7 & 99.7 & 99.4 & 88.3 & 99.7 & 99.7 & 99.7 & 100.0 & 10 \\
\hline 11 & 0.0 & 0. & 0 & 0 & 0. & 0 & 0 & 0. & 0. & 0.0 & & 99.7 & 99.7 & 99.7 & 99.4 & 3.3 & 99.7 & 99.7 & 9.7 & .0 & 11 \\
\hline 12 & 0.3 & 0.3 & 0.3 & 0.3 & 0.3 & 0.3 & 0.3 & 0.3 & 0.3 & 0.3 & 0.3 & & 100.0 & 100.0 & 99.7 & 87.9 & 100.0 & 100.0 & 100.0 & 99.7 & 12 \\
\hline 13 & 0.3 & 0.3 & 0.3 & 0.3 & 0.3 & 0.3 & 0.3 & 0.3 & 0. & 0.3 & 0.3 & 0.0 & & 100.0 & 99.7 & 87.9 & 100.0 & 100.0 & 100.0 & 99.7 & 13 \\
\hline 14 & 0.3 & 0.3 & 0.3 & 0.3 & 0.3 & 0.3 & 0.3 & 0.3 & 0.3 & 0.3 & 0.3 & 0.0 & 0.0 & & 99.7 & 87.9 & 100.0 & 100.0 & 100.0 & 99.7 & 14 \\
\hline 15 & 0.6 & 0.6 & 0.6 & 0.6 & 0.6 & 0.6 & 0.6 & 0.6 & 0.6 & 0.6 & 0.6 & 0.3 & 0.3 & 0.3 & & 87.9 & 99.7 & 99.7 & 99.7 & 9.4 & 15 \\
\hline 16 & 13.0 & 13.0 & 13.0 & 13.0 & 13.0 & 13.0 & 13.0 & 13.0 & 13.0 & 13.0 & 13.0 & 13.3 & 13.3 & 13.3 & 13.3 & & 87.9 & 87.9 & 87.9 & 88.3 & 16 \\
\hline 17 & 0.3 & 0.3 & 0.3 & 0.3 & 0.3 & 0.3 & 0.3 & 0.3 & 0.3 & 0.3 & 0.3 & 0.0 & 0.0 & 0.0 & 0.3 & 13.3 & & 100.0 & 100.0 & 99.7 & 17 \\
\hline 18 & 0.3 & 0.3 & 0.3 & 0.3 & 0.3 & 0.3 & 0.3 & 0.3 & 0.3 & 0.3 & 0.3 & 0.0 & 0.0 & 0.0 & 0.3 & 13.3 & 0.0 & & 100.0 & 99.7 & 18 \\
\hline 19 & 0.3 & 0.3 & 0.3 & 0.3 & 0.3 & 0.3 & 0.3 & 0.3 & 0.3 & 0.3 & 0.3 & 0.0 & 0.0 & 0.0 & 0.3 & 13.3 & 0.0 & 0.0 & & 99.7 & 19 \\
\hline 20 & 0.0 & 0.0 & 0.0 & 0.0 & 0.0 & 0.0 & 0.0 & 0.0 & 0.0 & 0.0 & 0.0 & 0.3 & 0.3 & 0.3 & 0.6 & 13.0 & 0.3 & 0.3 & 0.3 & & 20 \\
\hline & 1 & 2 & 3 & 4 & 5 & 6 & 7 & 8 & 9 & 10 & 11 & 12 & 13 & 14 & 15 & 16 & 17 & 18 & 19 & 20 & \\
\hline
\end{tabular}

Fig. 2. Comparative analysis of the nucleotide sequences of the eaeA gene of NE- Indian isolates with other published sequences showing the percentage homology 


\section{Discussion}

The study provides a systematic report of the prevalence of aEPEC strains causing infection in piglets along with molecular, serological and antimicrobial profiles of EPEC isolates and phylogenetic analysis of selected strains. Our findings showed all the isolated EPEC to be atypical, due to the lack of a $b f p$ plasmid gene, as proven by the specific PCR result. Atypical EPEC strains have diverse virulence factors and form a heterogeneous group that may have acquired the locus of enterocyte effacement (LEE) through horizontal transfer or may be previously tEPEC strains that have lost the adherence factor plasmid. Whether typical or atypical EPEC are more pathogenic is still insufficiently investigated, but nevertheless it has been proven that in addition to virulence factors coded in the LEE, intimin, E. coli secreted proteins, translocated intimin receptor, and type 3 secretion system, aEPEC strains can also express enteroaggregative heat-stable toxin 1 , enterohaemolysin, afimbrial adhesion, and other factors $(7,29)$. Some researchers $(10,16)$ reported higher detection of atypical than typical strains from animals and poultry; however, low detection of aEPEC from piglets $(1.6 \%)$ and infants $(0.6 \%)$, was also reported (3), and these contrasting results indicate that the distribution of typical and atypical EPEC varies.

Diverse serotypes were detected in this study that differed from the findings of other authors $(3,11)$. The recovery of EPEC in the $\mathrm{O} 1$ and $\mathrm{O} 111$ serogroups from piglets may be an indication of potential emerging serogroups in India as they do not classify into the commonest porcine pathogenic serogroups (11). Therefore, it is uncertain, whether these particular serogroups are specific to pigs. Atypical EPEC are adapted to both human and animal hosts, and hence proper diagnostic procedure should be followed when food-borne infection is suspected $(19,30)$. In this study, the recovery of EPEC belonging to O26, O55, O111, and $\mathrm{O} 114$ is corroborated by the World Health Organisation report of established EPEC serogroups (5). A high number of EPEC isolates (19.0\%) remained untypable, which indicates the occurrence of a wide spectrum of $E$. coli serogroups in India, as also reported by Dutta et al. (10) in diarrhoeic piglets.

Pork is the major source of protein for human consumption in northeastern India, where people in the countryside rear 5 to 10 pigs near their houses and in most cases share a source of water, hence there is probably a high risk of transmission of EPEC infection in the region. In our findings, the variation in EPEC infection being higher in unorganised farming and in crossbred may possibly be because the local piglets of nondescript breed possess better innate protection against natural infection than crossbred animals. The weaning age of local piglets is generally 10 weeks rather than the much shorter 6 weeks weaning period of crossbred piglets on organised farms; hence, maternal immunity might play an important role in resisting the infection in piglets. Lack of scientific literature regarding the prevalence of EPEC; prevented us from comparing our results to precedents. However, similar findings were reported in a prevalence study of diarrhoeagenic bacterial and viral pathogens $(17,18)$.

Antimicrobial drug resistance in enteric bacteria is a serious problem globally in both human and veterinary medicine. Food animals such as pigs may act as a reservoir or a potential source for dissemination of resistant bacterial populations in the environment. Enterobacteriaceae resistance to cephalosporins is mainly due to the production of extended-spectrum beta-lactamases which have been increasingly detected in food animals and have gained considerable attention worldwide (27). Imipenem is a carbapenem class of beta-lactams that is known to have a wide spectrum of activity against Gram-positive and Gram-negative bacteria and hence, any decrease in susceptibility to it should be taken seriously. None of the isolates in the study were found to be resistant to imipenem, which concurs with the findings of researchers from other countries $(2,20)$. There is a variation in resistance to streptomycin, ampicillin, cefotaxime, ceftriaxone, and ceftazidime when compared to the findings of other researchers $(21,23,25)$. This variation might be due to the EPEC investigated in this study having acquired the drug resistance gene through horizontal transfer because of indiscriminate use of antibiotics. Imipenem is not in use in northeastern India and other drugs such as ceftriaxone, cefotaxime, and ciprofloxacin have limited usage due to their high cost. This probably explains the bacterium's higher susceptibility of these drugs in the region. However, amoxicillin, cephalexin, enrofloxacin, and ampicillin are commonly used in veterinary practices in the North Eastern Region of India since they are easily available, which may contribute to the selection of EPEC-resistant variants. Multiple antimicrobial resistance in EPEC may partly result from the spread of genetic elements including plasmids, transposons, and integrons (26), and if it does, this may complicate any future drug therapy. Hence, regular monitoring of antimicrobial resistance among enteric pathogens, and particularly the foodborne kind, is a priority matter as resistant genes can be transferred to other pathogenic microorganisms.

The 100\% sequence homology among the EPEC isolates of our study suggests that genetically similar strains are widely distributed in the region; the sequence diversity is less than that of other reported sequences retrieved from the NBCI database. More studies need to be carried out on the eaeA gene and its molecular epidemiology, as there is a paucity of published eaeA sequences of porcine origin. Analysis of phylogenetic trees together with epidemiological data can be used to determine the relationship between different isolates at different point of time or space and to thereby track the origin of a disease. 
It may be stated that EPEC with different serotypes are persistently associated with piglet diarrhoea in northeastern India and more prevalent in the unorganised farming system. Based upon the sequence analysis, the selected isolates are uniquely placed in a separate clade. Taking into account the large pork consumption and close contact between the human and pig populations, the research findings warrant a more critical appraisal of EPEC and more emphasis on epidemiological study of all pathotypes with particular attention to antimicrobial drug resistance.

Conflict of Interests Statement: The authors declare that there is no conflict of interests regarding the publication of this article.

Financial Disclosure Statement: The study was supported by the Department of Biotechnology Advanced Animal Diagnostic and Management Consortium project, as Government of India funding through grant no. DBT-NER/LIVS/11/2012, dated $24 / 04 / 2014$

Animal Rights Statement: None required.

Acknowledgements: The authors are thankful to the Department of Biotechnology, Government of India for funding the study and to the Dean of College of Veterinary Sciences and Animal Husbandry, Selesih, Mizoram, for all the facilities made available for use in carrying out the research work.

\section{References}

1. Alikhani M.Y., Mirsalehian A., Aslani M.: Detection of typical and atypical enteropathogenic Escherichia coli (EPEC) in Iranian children with and without diarrhea. J Medical Microbiol 2006, 55, 1159-1163.

2. Aly M.E.A., Essam T.M., Amin M.A.: Antibiotic resistance profile of E. coli strains isolated from clinical specimens and food samples in Egypt. Int Microbiol Res 2012, 3, 176-182.

3. Begum J., Dutta T.K., Chandra R., Choudhary P.R., Varte Z., Bitew M.: Molecular and phenotypic characterization of shigatoxigenic Escherichia coli (STEC) and enteropathogenic E. coli (EPEC) from piglets and infants associated with diarrhoea in Mizoram, India. African J Biotech 2014, 13, 1452-1461.

4. Belanger L., Garenaux A., Harel J., Boulianne M., Nadeau E., Dozois C.M.: Escherichia coli from animal reservoirs as a potential source of human extraintestinal pathogenic E. coli. FEMS Immunol Med Microbiol 2011, 62, 1-10.

5. Blanco M., Blanco J.E., Dahbi G., Mora A., Alonso M.P., Varela G., Gadea M.P., Schelotta F., Gonzalez E.A., Blanco J.: Typing of intimin (eae) genes from enteropathogenic Escherichia coli (EPEC) isolated from children with diarrhea in Montevideo, Uruguay: identification of two novel intimin variants ( $\mu \mathrm{B}$ and $\varepsilon \mathrm{R} / \beta 2 \mathrm{~B}$ ). J Med Microbiol 2006, 5, 1165-1174.

6. Bueris V., Huerta-Cantillo J., Navarro-Garcia F., Ruiz R.M., Cianciarullo A.M., Elias W.P.: Late establishment of the attaching and effacing lesion caused by atypical enteropathogenic Escherichia coli depends on protein expression regulated by Per. Infect Immun 2015, 83, 379-388.
7. Clinical Laboratory Standards Institute: Performance standards for antimicrobial susceptibility testing; Twenty-third informational supplement. CLSI document M100-S23. Clinical Laboratory Standards Institute, Wayne, PA, 2013.

8. Cortes C., De la Fuente R., Blanco J., Blanco M., Blanco J.E., Dhabi G., Mora A., Justel P., Contreras A., Sanchez A., Corrales J.C., Orden J.A.: Serotypes, virulence genes and intimin types of verotoxin-producing Escherichia coli and enteropathogenic E. coli isolated from healthy dairy goats in Spain. Vet Microbiol 2005, 110, 67-76.

9. Dhanashree B., Mallya P.: Detection of shiga-toxigenic Escherichia coli (STEC) in diarrhoeagenic stool and meat samples in Mangalore, India. Ind J Med Res 2008, 128, 271-277.

10. Dutta S., Krishnamurthy G.V., Raghavan R.: Serotyping and drug susceptibility of Escherichia coli isolates from diarrhoeic unweaned piglets. Ind Vet J 2001, 78, 573-575.

11. Dutta T.K., Roychoudhury P., Bandyopadhyay S., Chandra R.: Detection and characterization of Shigatoxigenic Escherichia coli from piglets with or without diarrhoea in Mizoram. Ind J Animal Sci 2011, 81, 899-903.

12. Ewing W.H.: Edward and Ewing's Identification of Enterobacteriaceae. Elsevier, New York, 1986, pp. 93-172.

13. Frohlicher E., Krause G., Zweifel C., Beutin L., Stephan R.: Characterization of attaching and effacing Escherichia coli (AEEC) isolated from pigs and sheep. BMC Microbiol 2008, 8, 144.

14. Hornitzky M.A., Mercieca K., Bettelheim K.A., Djordjevic S.P.: Bovine feces from animals with gastrointestinal infections are a source of serologically diverse atypical enteropathogenic Escherichia coli and Shiga toxin-producing E. coli strains that commonly possess intimin. Appl Env Microbiol 2005, 71, 3405-3412.

15. Jafari A., Aslani M.M., Bouzari S.: Escherichia coli a brief review of diarrhoeagenic pathotypes and their role in diarrheal diseases in Iran. Iran J Microbiol 2012, 4, 102-117.

16. Krause G., Zimmermann S., Beutin L.: Investigation of domestic animals and pets as a reservoir for intimin (eae) gene positive Escherichia coli types. Vet Microbiol 2005, 106, 87-95.

17. Kylla H., Dutta T.K., Kawlni L.: Prevalence and molecular characterization of Shigatoxigenic Escherichia coli in piglets of North East Region of India. Int J Trop Dis Health 2017, 27, 1-8.

18. Kylla H., Dutta T.K., Roychoudhury P., Mandakini R., Subudhi P.K.: Detection and characterization of Genogroup 5 Rotavirus associated with piglet diarrhoea in the North East Region of India. Vet Arhiv 2018, 88, 453-466.

19. Martins F.H., Guth B.E.C., Piazza R.M.F., Elias W.P., Leao S.C., Marzoa J., Dahbi G., Mora A., Blanco M., Blanco J., Pelayo J.S.: Lambs are an important source of atypical enteropathogenic Escherichia coli in southern Brazil. Vet Microbiol 2016, 196, 72-77.

20. Marwa E.A.A., Tamer M.E., Magdy A.M.: Antibiotic resistance profile of $E$. coli strains isolated from clinical specimens and food samples in Egypt. Int J Microbiol Res 2012, 3, 176-182.

21. Mazurek J., Bok E., Pusz P., Stosik M., Baldy-Chudzik K.: Phenotypic and genotypic characteristics of antibiotic resistance of commensal Escherichia coli isolates from healthy pigs. Bull Vet Inst Pulawy 2014, 58, 211-218.

22. Paton J.C., Paton A.W.: Pathogenesis and diagnosis of Shiga toxin-producing E. coli infections. Clin Microbiol Review 1998, $11,450-479$

23. Rosengren L.B., Waldner C.L., Reid-Smith R.J., Checkley S.L., McFall M.E., Rajic A.: Antimicrobial resistance of fecal Escherichia coli isolated from grow-finish pigs in 20 herds in Alberta and Saskatchewan. Canadian J Vet Res 2008, 72, $160-167$.

24. Rugeles L.C., Bai J., Martinez A.J., Vanegas M.C., Duarte O.G.G.: Molecular characterization of diarrhoeagenic Escherichia coli strains from stools samples and food products in Columbia. Int J Food Microbiol 2010, 138, 282-286.

25. Sasirekha B., Manasa R., Ramya P., Sneha R.: Frequency and antimicrobial sensitivity pattern of extended spectrum 
$\beta$-lactamases producing E. coli and Klebsiella pneumoniae isolated in a tertiary care hospital, Al Ameen. J Med Sci 2010, 3, 265-267.

26. Schroeder C.M., Zhao C., Debroy C., Torcolini J., Zhao J., White D.G.: Antimicrobial resistance of Escherichia coli 0157:H7 isolated from humans, cattle, swine and food. Appl Envir Microbiol 2002, 68, 576-581.

27. Smet A., Martel A., Persoons D., Dewulf J., Heyndrickx M., Herman L., Haesebrouck F., Butaye P.: Broad-spectrum betalactamases among Enterobacteriaceae of animal origin molecular aspects, mobility, and impact on public health. FEMS Microbiol Review 2010, 34, 95-316.

28. Spano L.C., Daniela A.I., Sadovsky A.D.I., Segui P.N., Saick K.W., Kitagawa S.M.S., Pareira F.E.L.: Age-specific prevalence of diffusely adherent Escherichia coli in Brazilian children with acute diarrhea. J Med Microbiol 2008, 57, 359-363.
29. Tennant S.M., Tauschek M., Azzopardi K., Bigham A., BennettWood V., Hartland E.L., Qi W., Whittam T.S., RobinsBrowne R.M.: Characterization of atypical enteropathogenic E. coli strains of clinical origin. BMC Microbiol 2009, 9, $117-121$

30. Trabulsi L.R., Keller R., Gomes T.A.T.: Typical and atypical enteropathogenic Escherichia coli. Emerg Infect Dis 2002, 8, 508-513.

31. Wang Q., Ruan X., Wei D., Hu Z., Wu L., Yu T., Feng L., Wang L.: Development of a serogroup specific multiplex PCR assay to detect a set of Escherichia coli serogroups based on the identification of their O-antigen gene clusters. Mol Cell Probes 2010, 24, 286-290.

32. Wieler L.H., Vieler E., Erpenstein C., Schlapp T., Steinruck H., Bauerfeind R., Byomi A., Baljer G.: Shiga toxin-producing Escherichia coli strains from bovines: association of adhesion with carriage of eae and other genes. J Clin Microbiol 1996, 34, 2980-2984. 